\title{
Comparison of two light guide tips used to photo-polymerize two dental composites. An in-vitro study
}

SADJ March 2019, Vol. 74 No. 2 p67 - p72

V Bookhan', S Arnold², MFG Dannheimer ${ }^{3}$, R Ballyram ${ }^{4}$

\section{ABSTRACT}

\section{Introduction}

Manufacturer-made light guide (MMLG) tips of light emitting diodes (LEDs) are frequently damaged. Could custom-made light guide (CMLG) tips be suitable replacements?

\section{Aims}

1.) To compare compressive fracture strengths of resinbased composite specimens photo-polymerized/ cured with a CMLG tip (acrylic-glass) and a MMLG tip (fibre-optic), used interchangeably on a poly-LED curing unit.

2.) To compare the costs of the CMLG tip and the MMLG tip.

\section{Methods}

Two groups of 20 composite cylindrical specimens (4 $\mathrm{mm}$ diameter, $4 \mathrm{~mm}$ length) were made in teflon moulds. Each light tip cured ten micro-hybrid $\mathrm{Z}_{100^{\mathrm{TM}}}$ and ten nano-filled Filtek ${ }^{\mathrm{TM}}$ Supreme XTE specimens, (60 seconds each side). Storage was in distilled water at $37^{\circ} \mathrm{C}\left( \pm 2^{\circ} \mathrm{C}\right)$ for 48 hours. Compressive strength testing (MPa) was done at a crosshead speed of $0.5 \mathrm{~mm} / \mathrm{min}$ using a Bencor Multi-T device in an Instron machine. Student's paired t-test and intra-class correlation coefficients (ICC) were applied for analysis and agreement testing. Relative costs of both light guide tips were determined and compared.

\section{Results}

Only the $\mathrm{Z100}{ }^{\mathrm{TM}}$ groups showed significant differences in compressive fracture strength $(p=0.001)$. The CMLG tip was cheaper.

\section{Author affiliations:}

1. Vinesh Bookhan: BDS, M Dent (Prosthodontics), Department of Odontology, School of Dentistry, University of Pretoria, South Africa.

2. Samantha Arnold: BChD, PG Dip Dent (Odontology), Department of Odontology, School of Dentistry, University of Pretoria, South Africa.

3. Mandfred Friedrich Gertges Dannheimer: M Dent (Pret) DTO (Pret), Department of Odontology, School of Dentistry, University of Pretoria, South Africa.

4. Raoul Ballyram: BDS, MDS, MPhil, PG Dip, Department of Periodontology and Oral Medicine, Sefako Makgatho Health Sciences University, School of Oral Health Sciences, South Africa. Corresponding author: V Bookhan

Department of Odontology, School of Dentistry, University of Pretoria, South Africa Tel: +27 (0)12 3192277 Email: vinesh.bookhan@up.ac.za

\author{
ACRONYMS \\ CMLG: $\quad$ Custom-Made Light Guide \\ LCU: $\quad$ Light Curing Unit \\ LED: $\quad$ Light Emitting Diode \\ MMLG: $\quad$ Manufacturer-Made Light Guide
}

\section{Discussion}

The CMLG tip was preferred for photo-curing Filtek ${ }^{\mathrm{TM}}$ Supreme XTE resin based composite.

The MMLG tip was preferred for photo-curing $Z 100^{\text {TM }}$ resin based composite.

\section{Conclusions}

The CMLG was suitable for curing preclinical Z100'M and Filtek $^{\text {TM }}$ Supreme XTE resins and was substantially cheaper than the MMLG tip.

\section{INTRODUCTION}

The use of a manufacturer-made Poly Light Emitting Diode (LED) LCU for the photo-polymerization (curing) of light cured resin based composites is well known to the dental profession. ${ }^{1-7}$ Polymerization of a resin based composite depends on an adequate output of light (minimum irradiance between $300-400 \mathrm{~mW} / \mathrm{cm}^{2}$ ). ${ }^{4}$ The output depends on the condition of the internal filter, condition and type of reflector, condition of the bulb LED and the condition and type of the light guide tip. Other factors include appropriate wavelength range and the exposure time of the light to the surface of the composite. ${ }^{2}$ It is also imperative that the irradiance wavelength of these LED dental curing units is compatible with the photo-initiator present in the resin based composite restoration. ${ }^{8-12}$ The amount of photo-initiator activated depends on the concentration in the material as well as the number and energy of the photons (wavelength of the curing light) to which the material is exposed. The most common photo-initiator today is camphorquinone which has a peak activity at around 470 nanometers.

The LED light guide tip forms part of the LCU and is responsible for the transmission, distribution and dispersion of light energy from the LED source to the surface of the resin based composite restoration. ${ }^{13-17}$ The transmission distribution and dispersion across the face (surface) of the light guide tip has a great impact on the polymerization kinetics of resin based composites. ${ }^{14,15,18,19}$ These factors can affect the polymerization shrinkage, associated stresses, micro-hardness, 
depth of cure, degree of conversion and water sorption of water soluble resin based composites, effects that may result in post-operative sensitivity, micro-leakage and restoration failure. ${ }^{14,15,20-23}$ It is therefore important that the light guide tip remains undamaged, clean and unobstructed so that it functions at an optimal level. MMLG tips are known to cure resin-based composites adequately. ${ }^{1-5}$ However they are extremely fragile and easily damaged by dental students performing pre-clinical restorative dental procedures.

Replacement of these damaged MMLG tips can be extremely expensive for dental schools and the ordering process can be a lengthy and arduous task. The delay also results in undergraduates having to share a LCU for pre-clinical procedures, compromising the efficiency of their pre-clinical education.

The efficacy of a CMLG tip (similar to the shape and dimensions of a MMLG tip) that allows the curing of a resin based composite to the status of sufficient compressive strength, similar to the compressive strength fracture of a human molar (305 $\mathrm{MPa}^{24}$ ) has not been investigated. This may be an alternative option, offering a suitable and inexpensive solution.

Therefore the aims of this study are;

i.) To evaluate the compressive fracture strength (MPa) values of specimens of two resin-based composite specimens (microhybrid $\mathrm{Z}_{100^{\mathrm{T}} \mathrm{M}}$ and nanofilled Filtek ${ }^{\mathrm{TM}}$ Supreme XTE) photo-cured with either a CMLG tip or a MMLG tip.

ii.) To compare the costs of the CMLG tip and the MMLG tip.

\section{MATERIALS AND METHODS}

\section{Technical specifications of the LED Unit}

The LED curing unit used for this study was a Light SLC-VIIIC (Hangzhou corporation, Zhejiang Province, China). The unit had an AC 90 adapter using a power source that delivered between $220 \mathrm{~V}$ and $230 \mathrm{~V}$ at a frequency that varied between $50 \mathrm{~Hz}$ and $60 \mathrm{~Hz}$. The power intensity (fast mode) of the LED unit was measured at $600 \mathrm{mw} / \mathrm{cm}^{2}$, using a radiometer as a guide.

The optical specification of the wavelength, as indicated by the manufacturer, was between 430nm and 490nm. These specifications ensured that the LED unit would be effective with both the resin based composite specimens and that the photo-initiator (camphoroquinone) present in the specimens would be activated.

Specimens were cured using the same LCU, the same power source and at the same room temperature of $18^{\circ} \mathrm{C}$. The light intensities through the CMLG tip and through the MMLG tip were tested, using the radiometer, before each specimen was cured, ensuring that curing was effected under the same conditions.

\section{Technical specifications of the light guide tips}

The MMLG tip was fibre-optic and the CMLG was acrylicglass. The light guide tips were $8 \mathrm{~mm}$ in diameter and
$10 \mathrm{~cm}$ in length, with a $145^{\circ}$ curved angle closer to the flat, polished tip.

\section{Specifications of the radiometer}

The radiometer used was a DEMETRON Model 100 Curing Radiometer (Demetron Research Corporation, Danbury, CT, USA). The radiometer reading instructions were listed on the rear surface of the radiometer as follows:

Readings under 200: Do not use the curing light, refer to instructions (for the curing light).

Readings in between 200-300: Increase the curing time.

Readings above 300: Use the curing light recommended time indicated by the manufacturer.

Technical specifications of the composite specimens

In this study one group of 20 composite cylindrical specimens (4 mm in diameter and $4 \mathrm{~mm}$ in length) were made of Filtek ${ }^{\text {TM }}$ Supreme XTE (3M ESPE Dental Products, St Paul, MN, USA). The other group of 20 composite specimens (4mm in diameter and $4 \mathrm{~mm}$ in length) were made from Z100'M (3M ESPE Dental Products, St Paul, MN, USA). The twenty composite specimens in each group were prepared using a machined teflon mould $4 \mathrm{~mm}$ in length and $4 \mathrm{~mm}$ in diameter.

Manufacturing of the CMLG tip and resin based composite specimens:

1. A custom mould made from polysiloxane lab putty (COLTENE, Essex, United Kingdom), was manufactured by taking an impression of the MMLG tip (Figure 1a) so that the dimensions and angles of the MMLG tip could be accurately transferred to the CMLG tip.

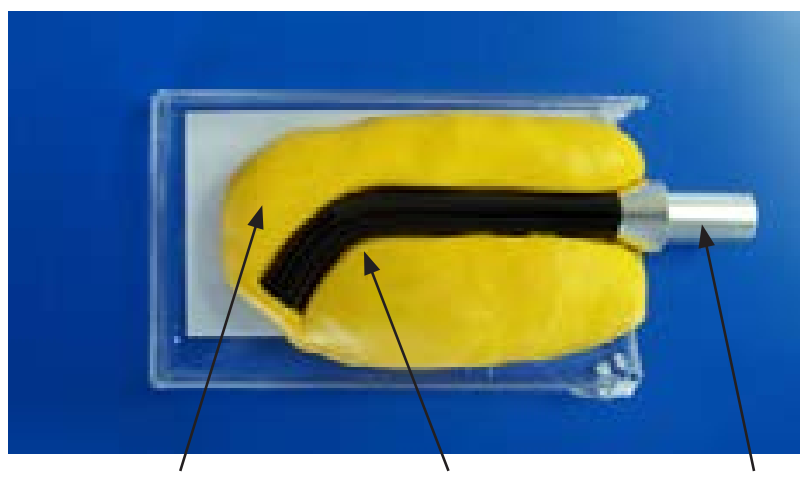

Figure 1a. Lab-putty impression of a MMLG fibre-optic tip with removable steel coupling.

2. A $2 \mathrm{~m}$ rod made of acrylic-glass (Plexiglas, Bedfordview, South Africa), $8 \mathrm{~mm}$ in diameter, was sectioned into $10 \mathrm{~cm}$ rods using a diamond disc on a straight hand-piece.

3. Each $10 \mathrm{~cm}$ acrylic glass rod was heated in a Bunsen burner flame (Science World, Parow Cape Town, South Africa) so it could be shaped into a 145 degree angle at the front end, using as a guide a custom 
mould made from polysiloxane lab putty (Coltene, Essex, United Kingdom) so the rod could be used as a light guide (Figure 1b).

The glass rod has a melting temperature of $130^{\circ} \mathrm{C}$. Extreme care was taken when shaping the light guide tip to avoid melting the rod. The light intensity of the CMLG tip was tested with the radiometer, before and after the structural reshaping.

There was no change in the transmission and intensity of the light. The CMLG rod was then finished (pumice and water) and polished (acrylic polish) in a Gamberini Polishing Machine (Gamberini corporation, Cambridgeshire, United Kingdom).

The smoothness of the surface of each end of the CMLG tip was evaluated using a Profilometer (Mitutoyo, Tokyo, Japan). The average of the Ra values (roughness coefficient) recorded were 0.259 which is well below the standard reference calibration value of 2.97 (according to the manufacturer) indicating high quality, polished surfaces at both ends of the CMLG tip.

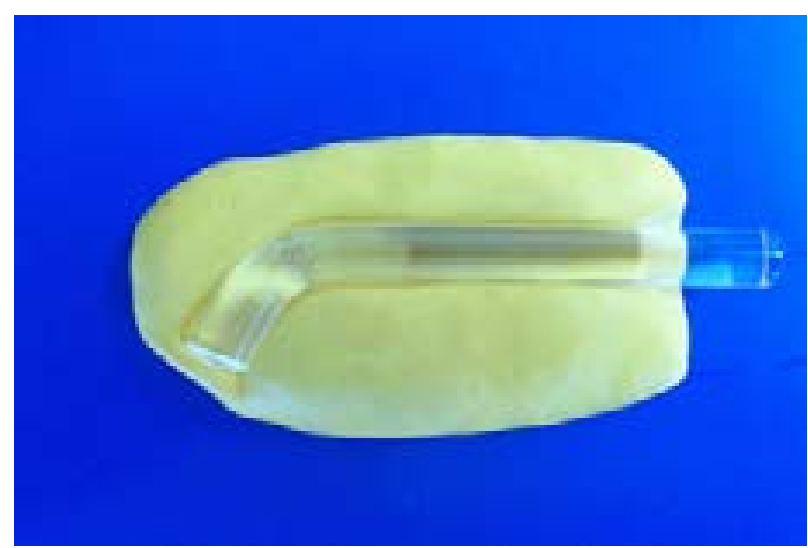

Figure 1b: Lab-putty mould used as a guide when shaping the CMLG acrylic-glass tip into a 145 degree angle.

4. The CMLG was fitted into the removable steel coupling that connected to the LED SLC-V IIIc Dental Curing Light (Hangzhou corporation, Zhejiang Province, China).

The CMLG tip was tested with the radiometer before each specimen was cured to ensure that light transmission was optimal to activate the photoinitiator and thus to cure each composite specimen.

5. Filtek ${ }^{\mathrm{TM}}$ Supreme XTE (A1) (3M ESPE) and Z100 ${ }^{\mathrm{TM}}$ (A1) (3M ESPE) composite were severally packed into and cured ( $2 \mathrm{~mm}$ increments) in machined circular teflon moulds (Figure 2) that were placed on a clear glass mixing slab.

The moulds were covered with a Mylar (Du Pont, Wilmington, USA) polyester strip, and light cured (60 seconds) on both sides to form cylindrical composite specimens ( $4 \mathrm{~mm}$ in diameter, $4 \mathrm{~mm}$ in length).

The flat face of the light guide tip was positioned directly over the polyester strip and onto the Teflon mould on both sides of the specimen. The distance between the tip face and the composite specimen was less than $0.5 \mathrm{~mm}$. The specimens were subsequently stored in distilled water at $37^{\circ} \mathrm{C}$ for 48 hours.

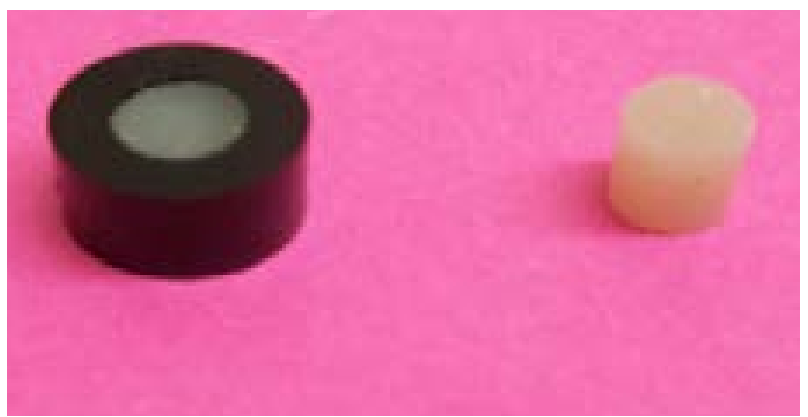

Figure 2: Composite specimens packed into Teflon moulds.

6. Two groups of twenty composite specimens $(n=40)$ were made using the Teflon moulds.

7. Ten $Z 100^{\mathrm{TM}}$ specimens were light-cured using a CMLG tip and ten $Z 100^{\mathrm{TM}}$ specimens with the MMLG tip

8. Ten Filtek ${ }^{\mathrm{TM}}$ Supreme XTE specimens were light-cured using a CMLG tip and ten Filtek ${ }^{\mathrm{TM}}$ Supreme XTE specimens with a MMLG tip.

9. The compressive strength of the specimens was determined, with the specimens mounted in a Bencor Multi-T device (Danville Engineering, San Ramon CA, U.S.A) placed in an Instron machine (Norwood Corporation, Massachusetts, U.S.A), at a crosshead speed of $0.5 \mathrm{~mm} / \mathrm{min}$ (Figure 3). Maximum compressive load (compressive strength) was measured in $\mathrm{MPa}$ at fracture of each specimen.

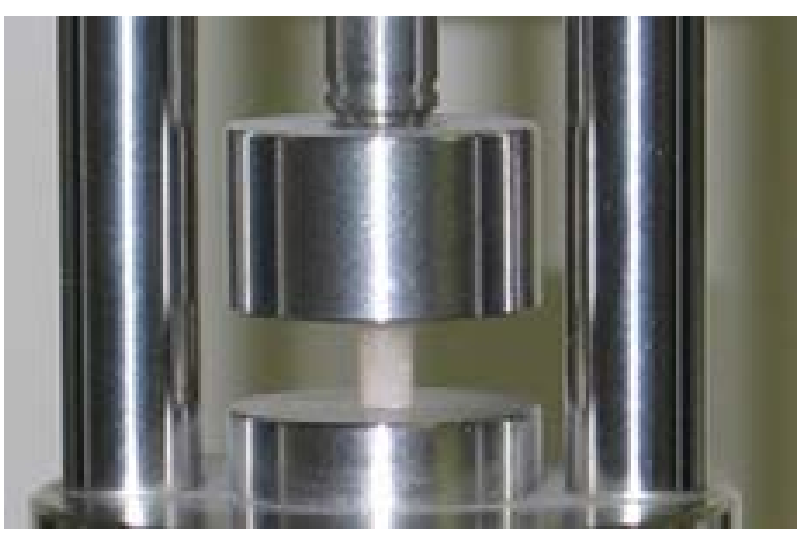

Figure 3: Instron machine with composite specimen mounted in a Bencor Multi-T device.

Results were compared and analysed using a Student's paired t-test. Agreement amongst the compressive fracture (MPa) values in each group was assessed with the intra-class correlation coefficient (ICC), a descriptive statistic that is a general measurement of agreement. The results for both specimens are presented in Tables 1 and 2 , which reflect a summary of the analyses.

The calculation of the cost difference of each light guide tip was determined by comparing the quote from the manufacturer for the MMLG tip with the total costs involved in the manufacturing of the CMLG tip. 
In this study the results of the specimens photo-cured with the MMLG tip acted as the control. The assumption is that MMLG tip, functioning optimally and used with a suitable LCU, will cure $\mathrm{Z100}^{\mathrm{TM}}$ and Filtek ${ }^{\mathrm{TM}}$ Supreme XTE resin specimens to an adequate degree. The mean compressive strength (MPa) value of the resin specimens photo-cured with the MMLG tip also served as the mechanical standard against which the mean compressive strength value (MPa) of the resin specimens photo cured with the CMLG tip were compared.

\section{RESULTS}

A) Compressive fracture strengths; Z100 ${ }^{\mathrm{TM}}$ composite

There were significant differences $(p=0.001)$ between the values of the mean compressive strengths (MPa) of the specimens in the $\mathrm{Z}_{100}{ }^{\mathrm{TM}}$ group. The mean compressive fracture strength at break for the specimens cured with the CMLG tip was 265.73 MPa and the mean compressive strength at fracture strength at break for the specimens cured with the MMLG tip was $348.47 \mathrm{MPa}$.

The coefficient of variation (CV) for specimens in the Z100 ${ }^{\mathrm{TM}}$ group was low (CMLG: 46\%; MMLG: 33\%) indicating consistency amongst the specimens within the group.

However, agreement amongst the MPa values assessed with the ICC, determined in a mixed-effects regression analysis, was found to be 0.58 implying moderate to poor agreement between the MPa values (since $0 \leq \mathrm{ICC} \leq 1$ with ICC = 1 being perfect agreement).

\begin{tabular}{|c|c|c|c|c|}
\hline $\begin{array}{l}\mathrm{Z100}{ }^{\mathrm{TM}} \\
\text { results }\end{array}$ & $\begin{array}{l}\text { CM } \\
\text { specimens }\end{array}$ & $\begin{array}{l}\text { MM } \\
\text { specimens }\end{array}$ & $\begin{array}{l}\text { Difference } \\
\text { (CM-MM) }\end{array}$ & p-value \\
\hline Median & 256.28 & 369.13 & -54.67 & \\
\hline $25^{\text {th }}$ percentile & 143.36 & 270.66 & -150.34 & \\
\hline $75^{\text {th }}$ percentile & 377.93 & 400.18 & -35.31 & \\
\hline Mean & 265.73 & 348.47 & -82.74 & $p=0.001$ \\
\hline $\begin{array}{l}\text { Standard } \\
\text { deviation }\end{array}$ & 121.15 & 114.35 & 82.38 & \\
\hline Minimum & 76.22 & 175.49 & -213.66 & \\
\hline Maximum & 439.73 & 556.03 & 44.78 & \\
\hline $\begin{array}{l}\text { Coefficient of } \\
\text { variation (CV) }\end{array}$ & $46 \%$ & $33 \%$ & & \\
\hline \multicolumn{5}{|c|}{ CV $(C M)=S D / M e a n=46 \%, C V(M M)=S D / M e a n=33 \%$} \\
\hline
\end{tabular}

\section{B) Compressive fracture strengths; Filtek ${ }^{\mathrm{TM}}$ Supreme XTE composite}

There were no significant differences $(p=0.147)$ between the mean compressive fracture strength (MPa) values of the specimens in the Filtek ${ }^{\mathrm{TM}}$ Supreme XTE group. The mean compressive fracture strength at break for the Filtek ${ }^{T M}$ Supreme XTE specimens cured with the CMLG tip was 330.33 MPa and the mean compressive fracture strength at break for the Filtek ${ }^{\mathrm{TM}}$ Supreme XTE specimens cured with the MMLG was 285.62MPa.

The coefficient of variation (CV) for the Filtek ${ }^{\mathrm{TM}}$ Supreme XTE group was low (CM: 28\%; MM: 33\%) indicating consistency amongst the specimens within the group.
However agreement amongst the $\mathrm{MPa}$ values was assessed with the ICC, determined in a mixed-effects regression analysis, and was found to be 0.27 , implying poor agreement between the MPa values (since $0 \leq \mathrm{ICC} \leq$ 1 with ICC = 1 being perfect agreement).

\begin{tabular}{|c|c|c|c|c|}
\hline $\begin{array}{l}\text { Filtek }{ }^{\mathrm{TM}} \\
\text { Supreme } \\
\text { XTE results }\end{array}$ & $\begin{array}{l}\text { CM } \\
\text { specimens }\end{array}$ & $\begin{array}{l}\text { MM } \\
\text { specimens }\end{array}$ & $\begin{array}{l}\text { Difference } \\
\text { (CM-MM) }\end{array}$ & p-value \\
\hline Median & 358.66 & 287.96 & 68.76 & \\
\hline $25^{\text {th }}$ percentile & 254.53 & 234.84 & -28.65 & \\
\hline $75^{\text {th }}$ percentile & 392.19 & 344.07 & 113.59 & \\
\hline Mean & 330.33 & 285.62 & 44.72 & $p=0.147$ \\
\hline $\begin{array}{l}\text { Standard } \\
\text { deviation }\end{array}$ & 94.02 & 70.68 & 97.46 & \\
\hline Minimum & 174.70 & 175.51 & -154.08 & \\
\hline Maximum & 477.86 & 385.98 & 153.82 & \\
\hline $\begin{array}{l}\text { Coefficient of } \\
\text { variation }(\mathrm{CV})\end{array}$ & $28 \%$ & $33 \%$ & & \\
\hline \multicolumn{5}{|c|}{$\mathrm{CV}(\mathrm{CM})=\mathrm{SD} / \mathrm{Mean}=28 \%, \mathrm{CV}(\mathrm{MM})=\mathrm{SD} / \mathrm{Mean}=33 \%$} \\
\hline
\end{tabular}

\section{C) Comparative costs}

The CMLG tip cost R 5 to manufacture and was significantly cheaper than the MMLG tip which cost R 1145 to purchase. Two hundred and thirty CMLG tips could be manufactured for the price of a single MMLG tip. Therefore in the event of breakage of or damage to a MMLG tip, a CMLG tip is the preferred option for replacement.

\section{DISCUSSION}

The conditions and specifications of an LCU and a light guide tip that allows adequate photo-polymerisation of resin based composite restorations is well known to the profession. ${ }^{24-30}$ These conditions and specifications have to be operating optimally, together with the appropriate light curing techniques, in order for the resin based composite restorations to be successfully cured. $4,14,23,24,29-37$

The wavelength of the LCU used in this experiment initiated activation of the photo-initiator in both resin specimens. The radiometer was used to test each light guide tip before each specimen was made, to ensure that the light intensity was sufficient to photo-polymerize each resin specimen. Light guide tips are an important part of the LCU since they are responsible for delivering (guiding) light from the LCU to the surface of the resin based composite. Compressive strength tests have been used previously to compare different MMLG tips. ${ }^{24}$

Resin based composites that are placed accurately under the appropriate conditions and cured adequately using appropriate techniques have a compressive strength that is able to resist the compressive forces of occlusion. ${ }^{24}$ The compressive fracture strength of a human molar is approximately $305 \mathrm{MPa}^{24}$ This value was used as the mechanical standard to compare the compressive fracture strengths (MPa values) of the $\mathrm{Z}_{100}{ }^{\mathrm{TM}}$ and Filtek ${ }^{\mathrm{TM}}$ Supreme XTE resin based composite specimens. 
The mean $\mathrm{MPa}$ value for the $\mathrm{Z} 100^{\mathrm{TM}}$ specimens light cured with the CMLG tip was 265.73 and the mean MPa value for the specimens cured with the MMLG tip was 348.47 MPa. The mean MPa of the $\mathrm{Z}_{100^{\mathrm{TM}}}$ specimens cured with the MMLG tip exceeded the mechanical standard of $305 \mathrm{MPa}$ indicating that the MMLG tip should be preferred for photo-polymerizing $\mathrm{Z}_{100^{\mathrm{TM}}}$ resin specimens.

The mean $\mathrm{MPa}$ value for the Filtek ${ }^{\mathrm{TM}}$ Supreme XTE specimens light cured with the CMLG tip was $330.33 \mathrm{MPa}$ and the mean $\mathrm{MPa}$ value for the specimens cured with the MMLG tip was 285.62 MPa. The mean MPa of the Filtek $^{\mathrm{TM}}$ Supreme XTE specimens cured with the CMLG tip exceeded the mechanical standard of $305 \mathrm{MPa}$ indicating that the CMLG tip should be preferred for photo-polymerizing Filtek ${ }^{\mathrm{TM}}$ Supreme XTE resin specimens.

The results indicate that the consistency of the specimens made and the repeatability of the study design was excellent (Coefficient of variation was $<50 \%$ in both groups). However the measured agreement amongst the compressive fracture (MPa) values in each group of specimens photo-cured with both light guide tips, was moderate to poor $\left(I C C=0.58\right.$ for $Z 100^{\text {TM }}$ and 0.27 for Filtek $^{\mathrm{TM}}$ Supreme XTE). The reasons for this poor agreement may be speculated as: 1) A small sample size and 2) uncontrollable variables within the resin, the light guide tips and the electricity supply, such as; i) the unknown quantity of the photoinitiator within each resin composite; ii) damage to the light guide tip such as breakage of the fibre-optic bundles and undetected light guide tip fractures and iii) electricity supply having a variable/ inconsistent line voltage. This may have resulted in partial curing and under-polymerization of the resin specimens ${ }^{36}$ within each group, resulting in compressive fracture strength values $(\mathrm{MPa})$ that have poor agreement.

The radiometer gauge indicated that the CMLG tip guided light from the LCU to the surface of each resin specimen slowly and gradually (the gauge of the radiometer moved at a slow and steady speed from 0 to $600 \mathrm{mw} / \mathrm{cm}^{2}$ that took approximately 5 seconds) until the maximum intensity was reached and sustained during the photoactivation process.

The radiometer gauge indicated that the MMLG tip guided light from the LCU to the surface of the resin specimens rapidly (the gauge of the radiometer moved with a sudden rapid surge from 0 to $600 \mathrm{mw} / \mathrm{cm}^{2}$ that took approximately one second) until the maximum intensity was reached and sustained during the photoactivation process.

The mean MPa values of $\mathrm{Z} 100^{\mathrm{TM}}$ and Filtek ${ }^{\mathrm{TM}}$ Supreme XTE groups suggest that the $Z 100^{\mathrm{TM}}$ specimens (cured with the MMLG tip) responded to the sudden rapid progress to maximum light intensity compared with the Filtek ${ }^{\mathrm{TM}}$ Supreme XTE specimens (cured with the CMLG tip) that "preferred" the gradual steady progress to maximum light intensity. Further studies are required to confirm these assumptions. The CMLG tip emitted very little heat energy, when touched with a forefinger, compared with the MMLG tip that emitted a substantial amount of heat energy, enough to cause tactile discomfort when touched.
The acrylic glass of the CMLG tip allowed heat to dissipate as light travelled along its length compared with the fibre-optic MMLG tip that did not allow heat to dissipate as light travelled along its length. The reasons for the different heat energy emissions and heat dissipations form each light guide tip was beyond the scope of this experiment and the aims of this study. Follow up studies will determine the reasons for this occurrence.

A comparison of the cost of each light guide tip indicate that the cost of the CMLG tip was significantly cheaper than the MMLG tip. The CMLG tips were easier to replace, available immediately and did not require a waiting period for delivery. The replacement process became extremely efficient. Students were allowed to progress efficiently with their pre-clinical training educational process.

\section{CONCLUSION}

The CMLG tip was preferred for curing Filtek ${ }^{\mathrm{TM}}$ Supreme XTE resin composite and the MMLG tip was preferred for curing $Z 100^{\mathrm{TM}}$ resin composite. The CMLG tip was suitable for curing pre-clinical $\mathrm{Z}_{100^{\mathrm{TM}}}$ and Filtek ${ }^{\mathrm{TM}}$ Supreme XTE resin based composite restorations. Further studies are required to determine whether the CMLG tip is suitable for clinical use on patients to cure Filtek ${ }^{\mathrm{TM}}$ Supreme XTE resin based composite restorations. The CMLG tip was easier to replace and is more cost efficient than the MMLG tip.

\section{Acknowledgements}

The authors would like to sincerely thank Prof P Becker for analysing the results of this study and Mr C Parsons for shaping and polishing the CMLG tip.

\section{Conflict of interest}

No conflict of interest declared.

\section{References}

1. Zorzin J, Maier E, Harre S, Fey T, Belli R, Lohbauer U, Petschelt A, Taschner M. Bulk-fill resin composites: Polymerization properties and extended light curing. Dent Mater. 2015;31:293-301.

2. Price RB, Ferracane $J L$ and Shortall AC. Light-Curing units: A review of what we know. JDR. 2015; 94(9):1179-86.

3. Alrahlah A, Silikas $N$ and Watts D. Post-cure depth of cure of bulk fill dental resin-composites. Dent Mater. 2014;30:149-54.

4. Price RB, Shortall AC and Palin WM. The contemporary issues in light curing. Oper Dentistry. 2014;39(1):4-14.

5. Kameyana A, Haruyama A, Asami M and Takahashi. Effect of emitted wavelength and light guide type on irradiance discrepancies in hand-held dental curing radiometers. Scientific World Journal 2013;647941:1-6.

6. Jandt KD and Mills R. A brief history of LED photopolymerization. Dent Mater.2013; 29:605-17.

7. Federlin $M$ and Price R. Improving light-curing instruction in dental school. J Dent Educ. 2012; 77(6):764-72.

8. Haenel T, Hausnerova B, Steinhaus J, Price RB, Sullivan, Moeginger. Effect of the irradiance distribution from light curing units on the local micro-hardness of the surface of dental resins. Dent Mater. 2015;31:93-104.

9. Li X, Pongprueksa, Van Meerbeek and De Munck J. Curing profile of bulk-fill resin-based composites. Dent Mater. 2015;43:664-72 
10. Price RB, Labrie D, Rueggeberg FA, Sullivan B, Kostylev I, Fahey J. Correlation between the beam profile from a curing light and the micro-hardness of four resins. Dent Mater. 2014;30:1345-57.

11. Santini A, Gallegos IT, Felix CM. Photo-initiators in dentistry: a review. Prim Dent J. 2013;2(4):30-3.

12. Ozturk B, Cobanoglu N, Cetin AR and Gunduz B. Conversion degrees of resin composites using different light sources. Eur Dent J. 2013;7:102-9.

13. Compressive strength of dental composites photo-activated with different light tips. Laser Phys. 2013;23:1-5.

14. Galvao MR, Caldas SGFR, Bagnato VS, de Souza Rastelli AN, de Andrade MF. Evaluation of degree of conversion and hardness of dental composites photo-activated with different light guide tips. Eur J Dent. 2013;7(1):86-93.

15. Arikawa H, Takahashi H, Minesaki Y, Muraguchi K, Matsuyama T, Kanie T, Ban S. A method for improving the light intensity distribution in dental light-curing units. Dent Mater J. 2011;30(2):151-7.

16. Malhotra N and Mala K. Light-curing considerations for resin-based composite materials: a review. Part I. Compend Contin Educ Dent. 2010;31(7):498-505.

17. Malhotra $\mathrm{N}$ and Mala K. Light-curing considerations for resin-based composite materials: a review. Part II. Compend Contin Educ Dent. 2010;31(8):584-8.

18. Corciolani G, Vichi A, Davidson CL, Ferrari M. The influence of tip geometry and distance on light-curing efficacy. Oper Dent. 2008;33(3):325-31.

19. Schattenberg A, Lichtenberg D, Stender E, Willershausen B, Claus-Peter E. Minimal exposure time of different LED-curing devices. Dent. Mater. 2008;24:1043-9.

20. Carvalho AA, Moreira FCL, Fonseca RB, Soares CJ, Franco EB, de Souza JB, Lopes LG. Effect of light sources and curing mode techniques on sorption, solubility and biaxial flexural strength of a composite resin. J Appl Oral Sci. 2012;20(2):246-52.

21. Jadhav S, Hegde V, Aher G, Fajandar N. Influence of light curing units on the failure of direct composite restorations. Conserv Dent. 2011;14(3):225-7.

22. Vandewalle K, Roberts HW,Rueggeberg FA. Power distribution across the face of different light guides and its effect on composite surface micro-hardness. J Esthet Restor Dent. 2008;20(2):108-17.

23. Vandewalle KS, Roberts HW, Andrus JL,Dunn WJ. Effect of light dispersion of LED curing lights on resin composite polymerization. J Esthet Restor Dent. 2005;17(4):244-54.

24. Galvao MR, Caldas SGFR, Calabrez-Filho S, Campos EA, Bagnato VS, Rastelli ANS, Andrde MF. Compressive strength of dental composites photo-activated with different light guide tips. Laser Phys. 2013;23 (1):1-5.

25. Price RB, Strassler HE, Seth S. The effectiveness of using a patient simulator to teach light-curing skills. JADA. 2014;145(1):32-43.

26. Federlin M, Price R. Improving light-curing instruction in dental school. J Dent Educ. 2013;77:764-72.

27. Price RB, Rueggeberg FA, Labrie D, Felix CM. Irradiance uniformity and distribution from dental light curing units. J Esthet Restor Dent. 2010; 22(2):86-101.

28. Ferracane JL. Power distribution across the face of different light guides and its effect on composite surface micro-hardness. J Esthet Dent. 2008;20(2):118-9.

29. Oberholzer G, Botha CT, duPreez IC. Advances in light curing units and curing techniques: a literature review. SADJ. 2005;60(10):451-4.

30. Mahn E. Clinical criteria for the successful curing of composite materials. Rev. Clin.Periodoncia Implantol. Rehabil. Oral. 2013;6(3):148-53.

31. Lempel E, Toth A, Fabian, Krajczar K. Szalma J. Retrospective evaluation of posterior direct composite restorations: 10-Year findings. Dent Mater. 2015;31:115-22.

32. Strydom C. Curing lights-the effects of clinical factors on intensity and polymerization. SADJ. 2002;57(5):181-6.
33. Arikawa H, Takahashi H, Minesaki Y, Muraguchi K, Matsuyama $\mathrm{T}$, Kanie T, Ban S. A method of improving the light intensity distribution in dental light curing units. Dent Mater $\mathrm{J}$. 2011;30(2):151-7.

34. Arikawa H, Kanie T, Fujii K, Takahashi H, Ban S. Effect of inhomogeneity of light curing units on the surface hardness of composite resin. Dent Mater J. 2008; 27 (1):21-8.

35. Santini A, Gallegos IT, Felix CM. Photo-initiators in dentistry: a review. Prim Dent J. 2014;2(4):30-3.

36. Solomon CS, Osman YI. Evaluating the efficacy of curing lights. SADJ. 1999;54(8): 357-61. 